\title{
Synthesis of Ruthenium(III) Phthalocyanine with Di-axial Bromo Ligands - A Promising Molecular Conductor with Giant Negative Magnetoresistance
}

\author{
Mario A.V. Gamboa ${ }^{a}$, Joey A.A. Valinton ${ }^{a}$ and Derrick E.C. Yu ${ }^{{ }^{a, b}}$
}

${ }^{a}$ Department of Chemistry, College of Science, De La Salle University, 2401 Taft Avenue, Manila, Philippines ${ }^{b}$ Materials Science and Nanotechnology Unit, De La Salle University, 2401 Taft Avenue, Manila, Philippines

\begin{tabular}{l}
\hline C H R O N I C L E \\
\hline Article history: \\
Received October 21, 2014 \\
Received in revised form \\
December 02, 2014 \\
Accepted 12 December 2014 \\
Available online \\
12 December 2014 \\
\hline Keywords: \\
Axially-ligated ruthenium \\
phthalocyanine \\
Molecular conductor \\
Giant negative \\
magnetoresistance \\
Molecular engineering
\end{tabular}

\begin{abstract}
A B S T R A C T
The electron transport of Phthalocyanines $(\mathrm{Pc})$ with central metal and di-axial ligands (such as $\mathrm{Fe}^{\mathrm{III}}(\mathrm{Pc}) \mathrm{L}_{2}$; where $\left.\mathrm{L}=\mathrm{CN}, \mathrm{Cl}, \mathrm{Br}\right)$ originates from its intermolecular $\mathrm{Pc} \pi-\pi$ orbital overlap while its giant negative magnetoresistance (GNMR) arises from its intramolecular Pc$\pi(\mathrm{HOMO})$ and $\mathrm{Fe}-d(s=1 / 2)$ interaction. However, the $\pi-d$ interaction tends to localize itinerant electrons resulting in the decrease in the conductivity of the $\mathrm{Fe}^{\mathrm{III}}(\mathrm{Pc}) \mathrm{L}_{2}$ series compared to the non-magnetic $\mathrm{Co}^{\mathrm{III}}(\mathrm{Pc}) \mathrm{L}_{2}$ where $\pi-d$ interaction is absent. More so, the axial ligand field energy of the $\mathrm{Fe}^{\mathrm{III}}(\mathrm{Pc}) \mathrm{L}_{2}$ system is found to have the ability to proportionally modulate the $\pi-d$ interaction. In reference thereof, theoretical calculations point that isostructural $\mathrm{Ru}^{\mathrm{III}}(\mathrm{Pc}) \mathrm{Br}_{2}$ would provide the best balance of $\pi$ - $d$ orbital energy interplay. That is, $\mathrm{Ru}^{\mathrm{III}}(\mathrm{Pc}) \mathrm{Br}_{2}$ is expected to be a molecule with high electrical conductivity and GNMR which would make it an ideal magnetic molecular conductor. This paper reports on the synthesis of $\mathrm{Ru}^{\mathrm{III}}(\mathrm{Pc}) \mathrm{Br}_{2}$.
\end{abstract}

\section{Introduction}

Phthalocyanines (Pc; Scheme 1a) are promising organic electrical conductors due to their fullyconjugated planar structure which result in effective electron delocalization. The incorporation of a central metal in the Pc molecule serves as coordination point of axial ligands $\left(\mathrm{M}(\mathrm{Pc}) \mathrm{L}_{2}\right.$; Scheme $\left.1 b\right)$ and paves way for slip-stacked solid state arrangement resulting in intermolecular electron transport brought about by the $\pi-\pi$ overlap between adjacent Pc's ${ }^{1}$. More so, chemical and physical properties of the Pc can be altered and engineered with the attachment of different central metals and axial ligands that modulate structural steric effects and ligand field energies thereby exhibiting varying electrical conductivity and giant negative magnetoresistance (GNMR) - properties that are paramount for functional organic materials ${ }^{1-3}$.

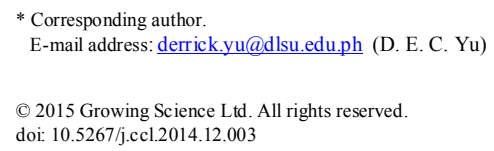




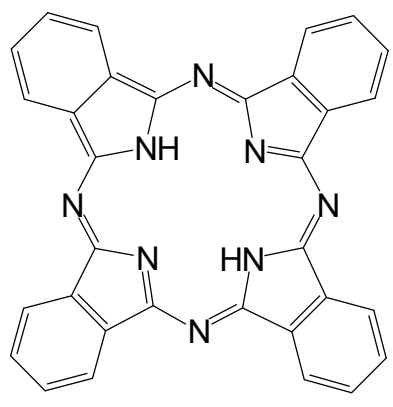

(a)

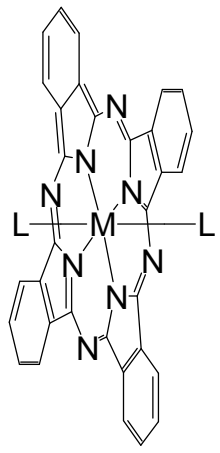

(b)

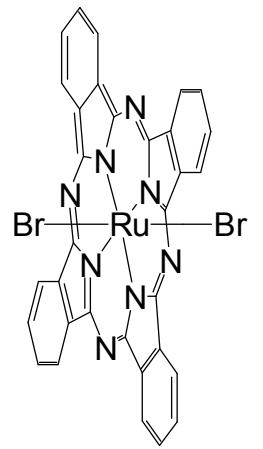

(c)

Scheme 1. Structures of (a) Phthalocyanine; (b) $\mathrm{M}(\mathrm{Pc}) \mathrm{L}_{2}$; (c) $\mathrm{Ru}(\mathrm{Pc}) \mathrm{Br}_{2}$

The non-magnetic $\mathrm{Co}^{\mathrm{III}}(\mathrm{Pc}) \mathrm{L}_{2}(\mathrm{~L}=\mathrm{CN}, \mathrm{Cl}, \mathrm{Br})$ system derives its electrical conductivity from the effectiveness of the intermolecular Pc $\pi-\pi$ overlap which are influenced by the steric factor of the axial ligands. Thus in the case of $\mathrm{Co}^{\mathrm{III}}(\mathrm{Pc}) \mathrm{L}_{2}$, the effectiveness of inter-Pc $\pi-\pi$ overlap $(\mathrm{L}=\mathrm{CN}>\mathrm{Cl}>\mathrm{Br})$ is directly proportional to electrical conductivity ${ }^{2}$. However, for the isostructural magnetic $\mathrm{Fe}^{\mathrm{III}}(\mathrm{Pc}) \mathrm{L}_{2}$ $(\mathrm{L}=\mathrm{CN}, \mathrm{Cl}, \mathrm{Br}$ ) system, electrical conductivity was diminished (up to 2-order decrease) compared with the $\mathrm{Co}^{\mathrm{III}}(\mathrm{Pc}) \mathrm{L}_{2}$ series but possesses GNMR of up to $95 \%$ decrease in electrical resistivity at $15 \mathrm{Tesla}^{3}$. Experimental data account that the intensity of the interaction between the Pc- $\pi(\mathrm{HOMO})$ and the magnetic $\mathrm{Fe}^{3+}-d$ orbitals in the $\mathrm{Fe}^{\mathrm{III}}(\mathrm{Pc}) \mathrm{L}_{2}$ system, which is in the order: $\mathrm{L}=\mathrm{CN}>\mathrm{Cl}>\mathrm{Br}$, causes the localization of itinerant electrons, thus revealing that the greater the $\pi$ - $d$ interaction, the more the conductivity is reduced. Furthermore, another key factor that influences the magnitude of the $\pi-d$ interaction is found to originate on the strength of the ligand field energy of the axial ligands $(\mathrm{L}=\mathrm{CN}$ $>\mathrm{Cl}>\mathrm{Br}$ ) which are directly attached to the central metal, and that the strength of ligand field energy is directly proportional to its influence on the intensity of the $\pi-d$ interaction $^{3}$.

A closer examination on the electronic structure of the $\mathrm{Fe}{ }^{\mathrm{III}}(\mathrm{Pc}) \mathrm{L}_{2}$ system revealed that the magnetic $\mathrm{Fe}^{3+}\left(d^{5} ; S=1 / 2\right)$ has an unpaired electron occupying one of doubly-degenerate $\left(d_{\mathrm{xy}}\right)^{2}\left(d_{\mathrm{xz}}\right)^{2}$ $\left(d_{\mathrm{yz}}\right)^{1}$ and $\left(d_{x y}\right)^{2}\left(d_{x z}\right)^{1}\left(d_{y z}\right)^{2}$ orbitals and the HOMO is a singly-occupied molecular orbital in the delocalized Pc- $\pi$ system. The scenario creates a unique intramolecular $\pi-d$ system while enabling the effect of the different field energies of the axial ligands $(\mathrm{CN}>\mathrm{Cl}>\mathrm{Br})$ to variably split the $\mathrm{Fe}^{3+} d$ orbitals, thereby affecting the energy difference between the HOMO (Pc- $\pi$ ) and the doubly-degenerate $\mathrm{Fe}^{3+} d_{\mathrm{xz}}$ and $d_{\mathrm{yz}}$ orbitals, resulting in the formation of an electronic state caused by the $\pi-d$ exchange interaction which hinders electron transport ${ }^{4}$. However, the said electronic state can be broken in certain degrees by external magnetic field ${ }^{3}$ - providing for a mechanism of the $\pi$ - $d$ interaction in the $\mathrm{Fe}^{\mathrm{III}}(\mathrm{Pc}) \mathrm{L}_{2}$ molecular conductor system, and thus resulting in a controllable and anisotropic GNMR. Hence, the magnetotransport mechanism can be isolated and solely engineered with intramolecular factors which is unique and less complicated as compared with the more common intermolecular $\pi$ - $d$ systems; intermolecular considerations are confined only to the $\pi$ - $\pi$ orbital overlap between adjacent $\mathrm{M}^{\mathrm{III}}(\mathrm{Pc}) \mathrm{L}_{2}$ systems which are rather constant and stable .

Substituting $\mathrm{Fe}^{3+}$ central metal of $\mathrm{Fe}^{\mathrm{III}}(\mathrm{Pc}) \mathrm{L}_{2}$ with a higher $d^{5}$ homologue, that is $\mathrm{Ru}^{3+}$, is expected to yield smaller energy difference $(\Delta E)$ between the localized $d$-spin and the unpaired $\pi$-electron (HOMO) in the Pc complex due to the fact that the $4 d$ electrons of $\mathrm{Ru}^{3+}$ are accommodated in higher energy levels than the $3 d$ electrons of $\mathrm{Fe}^{3+}$.

Ab initio calculations generated $\Delta E$ between the $\pi-d$ of Fe ${ }^{\mathrm{III}}(\mathrm{Pc}) \mathrm{L}_{2}$ system to be: $8.5450 \mathrm{eV}, 8.3839$ $\mathrm{eV}$, and $7.8655 \mathrm{eV}$ for $\mathrm{L}=\mathrm{Br}, \mathrm{Cl}$, and $\mathrm{CN}$, respectively; while for the $\mathrm{Ru}^{\mathrm{III}}(\mathrm{Pc}) \mathrm{L}_{2}$ series, $\Delta E$ are 
calculated to be: $\mathrm{CN}=3.7518 \mathrm{eV}, \mathrm{Cl}=3.8419 \mathrm{eV}, \mathrm{Br}=3.9411 \mathrm{eV}^{6}$, which are less than half of that of the $\mathrm{Fe}^{\mathrm{III}}(\mathrm{Pc}) \mathrm{L}_{2}$ series. Thus, experimental and theoretical considerations point out that the most ideallyengineered Pc-based molecular conductor with GNMR would be $\mathrm{Ru}^{\mathrm{III}}(\mathrm{Pc}) \mathrm{Br}_{2}$ (Scheme 1c) due to its optimally balanced $\pi-d$ interaction in consideration of the electron correlation effect associated with Pc-based 1-D anisotropic electron transport systems ${ }^{4,6}$.

Ruthenium phthalocyanine and its derivatives have been recognized to have promising solid-state properties, however, this class of compounds has not been studied in much detail because their labile nature made them very difficult to synthesize through the years ${ }^{7,8}$. The preparation of $\mathrm{Ru}^{\mathrm{III}}(\mathrm{Pc}) \mathrm{L}_{2}$, particularly $\mathrm{Ru}^{\mathrm{III}}(\mathrm{Pc}) \mathrm{Br}_{2}$, could result in a magnetic molecular conductor system that could achieve greater GNMR or could attain GNMR at significantly lower magnetic field than its already acceptable $\mathrm{Fe}^{\mathrm{III}}(\mathrm{Pc}) \mathrm{L}_{2}$ homologue.

\section{Results and Discussion}

Thionyl halides react with organometallic complexes and results into the oxidation of the central metal and halide ligation ${ }^{6,9}$. Thus in the conversion of $\mathrm{Ru}(\mathrm{Pc})$ into $\mathrm{Ru}(\mathrm{Pc}) \mathrm{Br}_{2}$, thionyl bromide $\left(\mathrm{SOBr}_{2}\right)$ was utilized for the oxidation of $\mathrm{Ru}^{2+}$ into $\mathrm{Ru}^{3+}$ to allow octahedral configuration and subsequently enable di-axial bromo ligation.

Mass spectrum recorded the following $\mathrm{m} / \mathrm{z}$ peaks (Fig. 1) which corresponds to the following fragments: $771.88=\left[\mathrm{Ru}(\mathrm{Pc}) \mathrm{Br}_{2}\right]($ calculated m/z: 773.43); $693.97=[\mathrm{Ru}(\mathrm{Pc}) \mathrm{Br}]($ calculated $\mathrm{m} / \mathrm{z}$ : 693.53); 614.06 $=[\mathrm{Ru}(\mathrm{Pc})]($ calculated $\mathrm{m} / \mathrm{z}: 613.63)$.

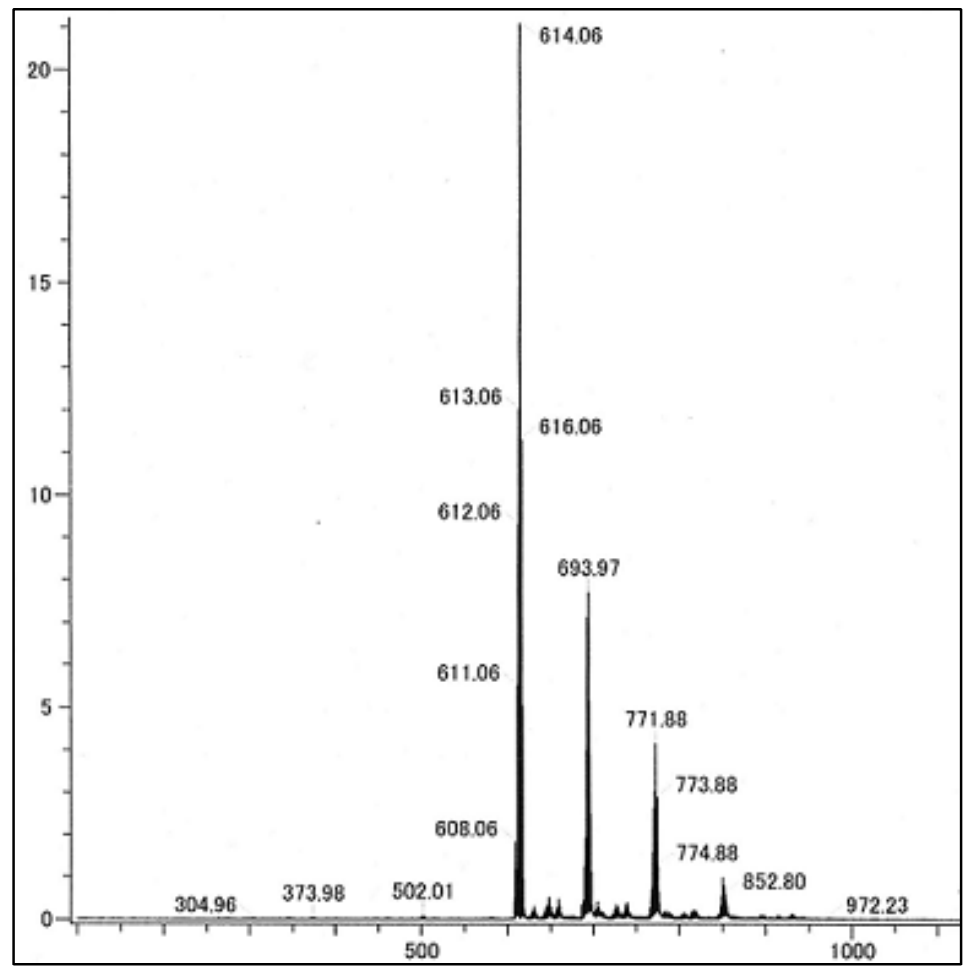

Fig. 1. Mass spectrum of $\mathrm{Ru}^{\mathrm{III}}(\mathrm{Pc}) \mathrm{Br}_{2}$.

The Pc moiety was confirmed by its characteristic Q and Soret bands at $665 \mathrm{~nm}$ and $360 \mathrm{~nm}$, respectively (Fig. 2). The Q and Soret absorption bands are attributed to $\pi$ - $\pi^{*}$ transitions of the Pc macrocycle, and the single Q-band peak signifies the attachment of central metal $(\mathrm{Ru})$ to the $\mathrm{Pc}^{8}$. 


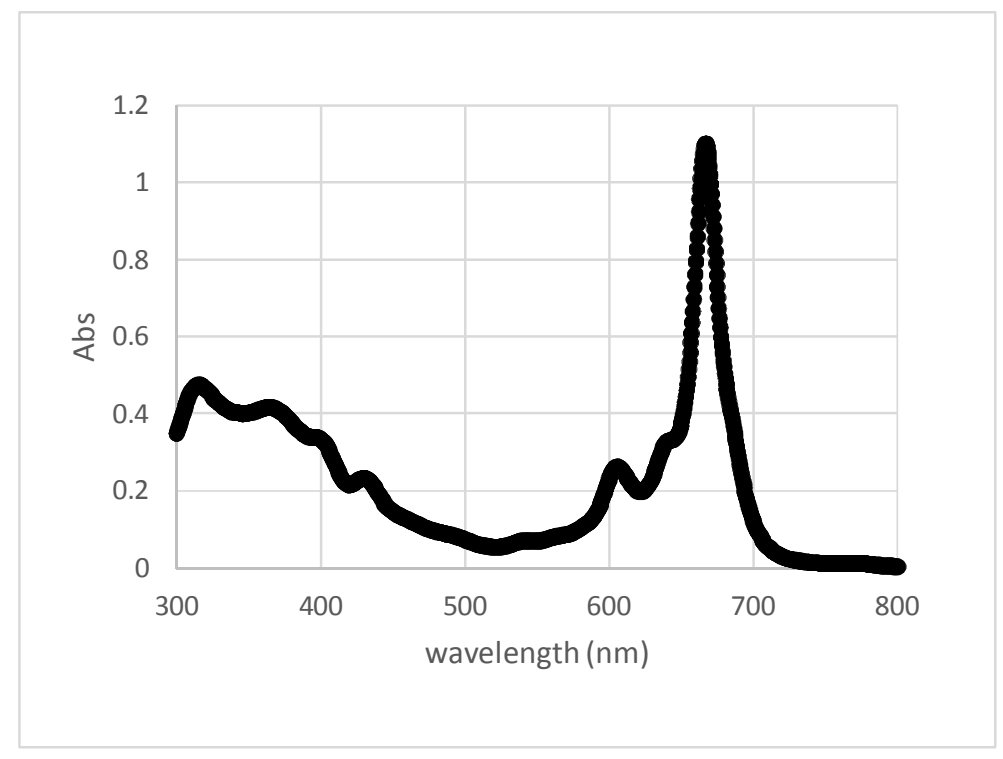

Fig. 2. UV-Vis profile of $\mathrm{Ru}^{\mathrm{III}}(\mathrm{Pc}) \mathrm{Br}_{2}$.

Energy dispersive X-ray (EDX) through a scanning electron microscope (SEM) was used to measure the $\mathrm{Ru}$ component. Generated data (Fig. 3) showed $14.3 \% \mathrm{Ru}$ mass component that empirically correlates to the Ru central metal.

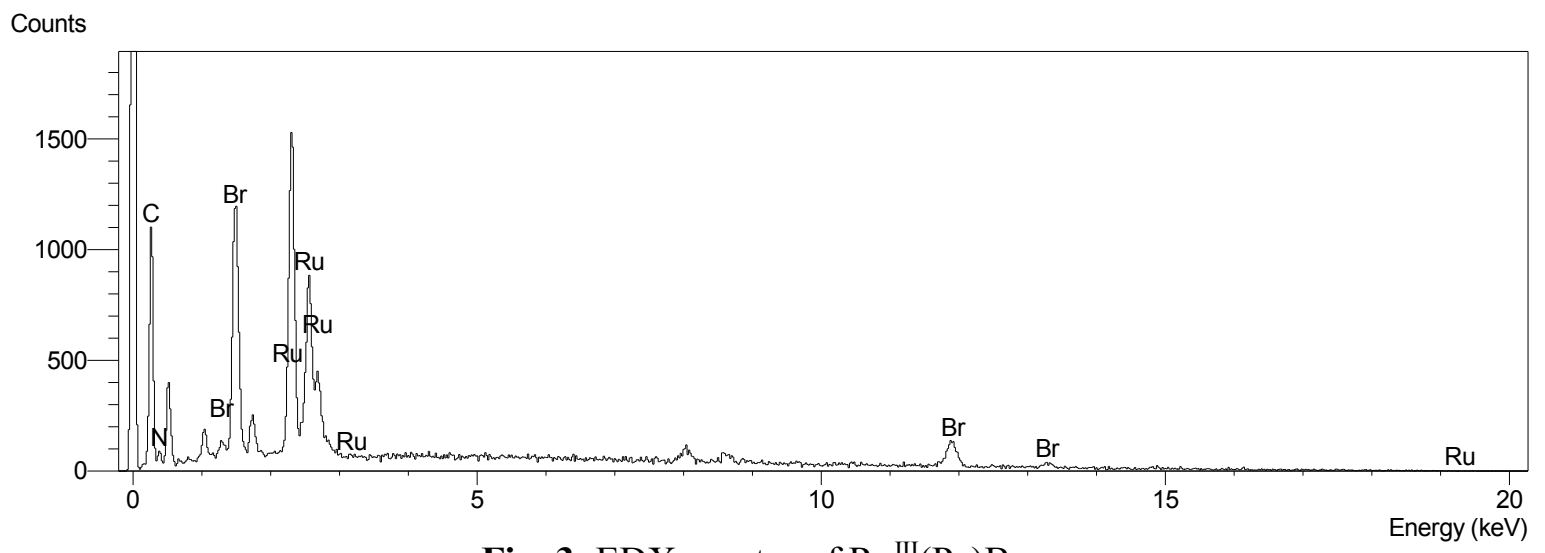

Fig. 3. EDX spectra of $\mathrm{Ru}^{\mathrm{III}}(\mathrm{Pc}) \mathrm{Br}_{2}$

The presence of di-axial bromo ligands was determined by ion chromatography which resulted in 17.4 mass percent corresponding to the two axial $\mathrm{Br}$ atoms attached to the $\mathrm{Ru}(\mathrm{Pc})$.

\section{Conclusions}

The successful synthesis of $\mathrm{Ru}^{\mathrm{III}}(\mathrm{Pc}) \mathrm{Br}_{2}$ which is deemed to be an ideal molecular conductor possessing anisotropic giant negative magnetoresistance based on theoretical and related experimental data $^{3}$ could now open the possibility for eventual solid-state synthesis (crystallization/intermolecular engineering ${ }^{1}$ ) and characterizations that will enable the study and utilization of its elusive and desirable materials properties. 


\section{Acknowledgements}

The authors would like to acknowledge the support and assistance of the University Research Coordination Office of De La Salle University and the Solid State Chemistry Laboratory (Prof. T. Inabe) of Hokkaido University, Japan.

\section{Experimental}

\subsection{Synthesis of Dibromophthalocyaninato(1-)ruthenium(III), $R u^{I I I}\left(P_{c}\right) B r_{2}$}

$\operatorname{RuPc}\left(1.0 \mathrm{~g}=\sim 0.001 \mathrm{~mol}\right.$; prepared using a reported procedure by Farrell et al. $\left.{ }^{10}\right)$ was suspended in nitrobenzene $(10 \mathrm{~mL})$. Thionyl bromide $(2 \mathrm{~mL}=\sim 0.01 \mathrm{~mol})$ was subsequently added to the reaction vessel and the mixture was refluxed for 5 hours at $60^{\circ} \mathrm{C}$ with constant stirring. The reaction product was then cooled to ambient temperature, subsequently filtered and washed several times with ethanol then finally dried in vacuum. The reaction afforded $\mathrm{Ru}^{\mathrm{III}}(\mathrm{Pc}) \mathrm{Br}_{2}$ as black powder $(60 \%$ yield).

\subsection{Chemical characterization}

Electrospray ionization (negative mode) mass measurement was acquired through Jeol JMST100LP mass spectrometer with 1:5 DMF:EtOH solvent system. UV-Vis characterization at 300-800 $\mathrm{nm}$ was measured in DMF using a JASCO Ubest V570 spectrophotometer. Bromine elemental analysis was obtained by ion chromatography using Dionex DX500 system. Ruthenium elemental analysis was done using an Oxford Energy Dispersive X-ray module attached to a Jeol JSM-5310 Scanning Electron Microscope.

\section{References}

1 Inabe T., and Tajima H. (2004) Phthalocyanines - versatile components of molecular conductors. Chem. Rev., 104, 5503-5534.

2 Yu D.E.C., Imai H., Ushio M., Takeda S., Naito T., and Inabe T. (2006) One-step synthesis of partially oxidized cobalt(III) phthalocyanine salts with axial ligands. Chem. Lett., 35, 602-603.

3 Yu D. E. C., Matsuda M, Tajima H., Kikuchi A., Taketsugu T., Naito T., and Inabe T. (2009) Variable magnetotransport properties in the $\mathrm{TPP}\left[\mathrm{Fe}(\mathrm{Pc}) \mathrm{L}_{2}\right]_{2}$ system $(\mathrm{TPP}=$ tetraphenylphosphonium, $\mathrm{Pc}=$ phthalocyaninato, $\mathrm{L}=\mathrm{CN}, \mathrm{Cl}$, and $\mathrm{Br})$. J. Mater. Chem., 19, 718-723.

4 Hotta C., Ogata M., and Fukuyama H. (2005) Interaction of the Ground State of Quarter-Filled One Dimensional Strongly Correlated Electronic System with Localized Spins. Phys. Rev. Lett. 95, 216402/1.

5 Yu D. E. C., Matsuda M, Tajima H., Naito T., and Inabe T. (2011) Stable $\pi-\pi$ dependent electron conduction band of TPP $\left[\mathrm{M}(\mathrm{Pc}) \mathrm{L}_{2}\right]_{2}$ molecular conductors $(\mathrm{TPP}=$ tetraphenylphosphonium; $\mathrm{M}=$ $\mathrm{Co}, \mathrm{Fe} ; \mathrm{Pc}=$ phthalocyaninato; L = CN, Cl, Br). Dalton Trans., 40, 2283-2288, 2011.

$6 \mathrm{Yu}$ D.E.C., Kikuchi A., Taketsugu A., and Inabe T. (2013) Crystal Structure of Ruthenium Phthalocyanine with Diaxial Monoatomic Ligand: Bis(Triphenylphosphine)Iminium Dichloro(Phthalocyaninato(2)) Ruthenium(III). Journal of Chemistry, 2013, 486318.

7 Subramanian L.R. (2000) Tribute to Professor Dr Michael Hanack. J. Porphyrins Phthalocyanines, 4, 300-309.

8 Rawling T., and McDonagh A. (2007) Ruthenium phthalocyanine and naphthalocyanine complexes: synthesis, properties and applications. Coord. Chem. Rev., 251, 1128-1157. 
9 Davies J.A., Hockensmith C.M., Kukushkin V.Yu, and Kukushkin Yu N. (1996) Non-traditional Oxidants in Preparative Coordination Chemistry. In Synthetic Coordination Chemistry: Principles and Practice. World Scientific, Singapore, 222-291.

10 Farrell N.P., Murray A.J., Thornback J.R., and Dolphin D.H., and James B.R. (1978) Phthalocyanine complexes of ruthenium(II). Inorg. Chim. Acta, 28, L144-L146. 